stopped completely again by the 26th day. He stopped using hypnotherapy after four weeks and he remains completely free of vomiting 12 months later. He has been seen for follow up, with his family, by his local child psychiatrist on three occasions.

\section{Discussion}

Self hypnotherapy using guided imagery was used as the primary treatment in this 9 year old boy. This exploited the high imaginative skills of children, which peak at the age of 9 years, and the related hypnotic ability. ${ }^{6}$ The imagery material was tailored to the child's own interests and age level, and he was involved interactively in the recording of the material. This involvement captured his interest and motivation, and encouraged an expectation of coping and control. It gave him a means of getting better 'with honour'. ${ }^{4}$

The use of a personal audio system allowed him to use the treatment in a private and personal manner, increasing the perception of his own control over his symptoms and treatment and separating him from family influences.

Behavioural techniques of contingency management were used as a secondary treat- ment. These techniques encouraged his parents to focus on his efforts to become well, reducing inappropriate parental attention and school avoidance, which are common patterns of behaviour observed in families of children with psychosomatic disorders. ${ }^{4}$ Local follow up over the following months allowed these issues to be addressed and may have been helpful in avoiding later relapses.

Self hypnosis has few or no side effects. It is more acceptable to patients and staff than the use of aversive stimuli. Its successful use in this case suggests that further studies are justified.

1 Schaefer CE, Millman HL, Levine GF. Therapies for psychoJossey-Bass, 1979.

2 Nakanishi DA, Anderson DR. Behavioral treatment of psychogenic vomiting among children - a review and case $17-20$.

3 Kohen D, Olness K, Colwell S, Heimel A. The use of ment of 505 pediatric behavioral encounters. Developmental and Behavioural Pediatrics 1984;5:21-5.

4 Bentovim A. Less orthodox approaches to behaviour problems in children. Arch Dis Child 1985;60:1198-201.

5 Zeltzer LK, Kellerman J, Ellenberg L, Dash J. Hypnosis for reduction of vomiting associated with chemotherapy and disease in adolescents with cancer. $\mathcal{F}$ Adolesc Health Care 1983;4:77-84.

6 Gardner GG, Olness K. Hypnosis and hypnotherapy with children. New York: Grune and Stratton, 1981. somatic disorders in children. San Francisco and London: example. I Psychosoc Nurs Ment Health Serv 1982;20. relaxation-mental imagery (self-hypnosis) in the manage-

\section{Glucose polymer regimens and hypernatraemia}

\author{
I G Verber, M Bain
}$$
3
$$

\begin{abstract}
A 3 year old boy who had glutaric aciduria diagnosed at 22 months of age was admitted with a history of lethargy, vomiting, and fever. He had been receiving glucose polymers as part of his dietary management. He was severely hypernatraemic, but after resuscitation and rehydration made a good recovery. The possible aetiology of his hypernatraemia is discussed.
\end{abstract}

Glucose polymers are being increasingly used as dietary supplements for children. They are particularly useful in the mangement of metabolic decompensation in disorders of amino acid metabolism such as glutaric aciduria. This is an inherited disorder of lysine and tryptophan metabolism caused by glutaryl coenzyme A dehydrogenase deficiency in which slowly progressive neurological deterioration is punctuated by episodes of metabolic decompensation that present with lethargy, vomiting, a reduced level of consciousness, and hypoglycaemia. The mainstay of treatment is a diet low in lysine and tryptophan; this reduces excretion of the metabolite but has a variable effect on the progress of the neurological deterioration. Episodes of metabolic decompensation are managed by stopping the dietary protein intake and giving glucose (usually in the form of a glucose polymer) to prevent hypoglycaemia and provide an alternative source of energy.

We report the case of a child with glutaric aciduria who was given this oral emergency regimen during an attack of gastroenteritis and subsequently developed severe hypernatraemia dehydration.

\section{Case report}

A 3 year old boy was admitted with a three day history of lethargy, vomiting, and fever. Glutaric aciduria had been diagnosed at the age of 22 months. He was on a diet in which his intake of tryptophan and lysine was carefully controlled. In response to these symptoms his parents had stopped his dietary protein intake and given him feeds of an oral glucose polymer (Maxijul, Scientific Hospital Supplies). They made this feed up to $20 \%$ strength (w/v) and to each $200 \mathrm{ml}$ they added a sachet of glucose electrolyte mixture (Dioralyte, Rorer); this provided an additional $35 \mathrm{mmol} / \mathrm{l}$ sodium and $40 \mathrm{~g} / 1$ glucose. He was given this feed every four hours at first, but as he became more dehydrated this was increased so that in the 24 hours before admission he had had nine feeds giving approximately $150 \mathrm{ml} / \mathrm{kg} /$ day. He had no additional free water. On the day of admission he had become extremely drowsy and developed profuse watery diarrhoea. 
Constituents of feeding regimens

\begin{tabular}{lccl}
\hline Substance & $\begin{array}{l}\text { Sodium } \\
\text { content } \\
(\text { mmol/l) })\end{array}$ & $\begin{array}{l}\text { Carbohydrate } \\
\text { content } \\
(\mathrm{g} / \mathrm{l})\end{array}$ & $\begin{array}{l}\text { Hypernatraemia } \\
\text { reported }\end{array}$ \\
\hline Oral rehydration fluid & 90 & 20 & $\mathrm{No}^{3}$ \\
Formula milk & 49 & 50 & Yes $^{1}$ \\
Lytren* & 50 & 100 & Yes $^{4}$ \\
Glucose mixture & $<20$ & 250 & Yes $^{5}$ \\
Maxijul 20\%† & 4 & 200 & This case \\
\hline
\end{tabular}

${ }^{*}$ Mead Johnson; †Scientific Hospital Supplies.

On examination he was floppy and semiconscious, with poor skin texture, sunken eyes, and a doughy abdomen. His weight on admission was $10.6 \mathrm{~kg}$ (compared with $12.4 \mathrm{~kg}$ in the clinic one month before)

Plasma sodium concentration was 182 $\mathrm{mmol} / \mathrm{l}$, potassium $4.9 \mathrm{mmol} / \mathrm{l}$, urea $6.2 \mathrm{mmol} / \mathrm{l}$, and glucose $8.3 \mathrm{mmol} / \mathrm{l}$. Serum osmolarity was $373 \mathrm{mmol} / \mathrm{l}$, and serum ammonia concentration $36 \mu \mathrm{mol} / \mathrm{l}$ (reference range $<50 \mu \mathrm{mol} / \mathrm{l}$ ). Acidbase balance showed a $\mathrm{pH}$ of $7 \cdot 44$, bicarbonate $21 \mathrm{mmol} / \mathrm{l}$, and base deficit 3. No pathogens were isolated from the stool.

He was resuscitated with plasma $20 \mathrm{ml} / \mathrm{kg}$ and then cautiously rehydrated with $5 \%$ dextrose and $0 \cdot 18 \%$ saline. His serum sodium concentration returned to normal within five days. Oral protein was restarted after 24 hours to minimise endogenous protein breakdown. $\mathrm{He}$ made a good recovery with no obvious deterioration in his neurological condition.

\section{Discussion}

Hypernatraemic dehydration is a common and potentially serious complication of gastroenteritis. It has been associated with artificial formula feeds, which have a high osmotic load, particularly if inappropriately made up. ${ }^{1}$ It is probable that the high carbohydrate content of these feeds is poorly absorbed during an attack of gastroenteritis, with the resulting loss of more water than sodium in the stools. ${ }^{2}$ The sodium content of the feed is relatively unimportant; indeed, oral rehydration fluids containing high concentrations of sodium have been successfully used to treat hypernatraemic dehydration. ${ }^{3}$ The sodium and carbohydrate contents of various feeds that have been reported to cause hypernatraemic dehydration is shown in the table, with that of the oral rehydration fluid for comparison. It is likely that the hyperosmolar feeds given to this child contributed to the development of hypernatraemia and his subsequent clinical deterioration.

The use of oral emergency regimens that include glucose polymers has undoubtedly improved the treatment of metabolic disease, but complications of such regimens are only now becoming apparent. One that has been recently reported was the catabolism of high carbohydrate feeds by gut bacteria in the colon to form proprionate, that was readily absorbed. This caused a worsening encephalopathy in a child with methylmalonic acidaemia. ${ }^{6}$ The occurrence of hypernatraemia is, however, related to osmotic load, and therefore children without metabolic disease are equally at risk. It is therefore important to emphasise the need to give adequate volumes of free water when using these feeds for nutritional support.

We thank Mrs A MacLean, senior paediatric dietician, St George's Hospital, for her helpful advice.

1 Chambers TL, Steele AE. Concentrated milk feeds and thei relation to hypernatraemic dehydration in infants. Arch $D$ is relation to hypernatraem.

2 Hirschhorn N. The therapy of acute diarrhoea in children Am 7 Clin Nutr 1980;33:637-63.

3 Anonymous. Oral glucose/electrolyte therapy for acute diarrhoea. Lancet 1975;i:79-80.

4 Colle E, Ayoub E, Raile R. Hyperosmolar dehydration (hypernatraemia): the role of feedings high in solutes Pediatrics 1958;22:5-12.

5 Ironside AG, Tuxford AF, Heyworth B. A survey of infantile gastroenteritis. $\mathrm{Br} \mathrm{Med} \mathcal{F}$ 1970; iii:20-4.

6 Walter JH, Leonard JV, Thompson GN, Halliday D, Bartlet K. Gut bacterial metabolism. Lancet 1988;ii:226.

\title{
Correction of hypernatraemia with continuous arteriovenous haemodiafiltration
}

\author{
G D Moss, R J Primavesi, M E McGraw, T L Chambers
}

\author{
Paediatric Department, \\ Southmead General \\ Hospital, \\ Westbury-on-Trym, \\ Bristol BS10 5NB \\ G D Moss \\ R J Primavesi \\ M E McGraw \\ T L Chambers \\ Correspondence to: \\ Dr McGraw. \\ Accepted 25 January 1990
}

(Arch DisChild 1990;65:628-30)

\begin{abstract}
Continuous arteriovenous haemodiafiltration was used successfully to achieve controlled correction of hypernatraemia in the presence of renal failure, when peritoneal dialysis was contraindicated, in a 4 year old girl.
\end{abstract}

To reduce the risk of neurological complications resulting from the correction of hypernatraemia, therapeutic measures should produce a gradual fall in plasma sodium concentration. ${ }^{1}$ This is difficult to achieve in the presence of renal failure. Peritoneal dialysis has been successfully used, ${ }^{2}$ but when this is contraindicated the alternative of haemodialysis results in a rapid, uncontrollable, fall in plasma sodium.

Since the development of haemofilters suitable for use in infants and children, continuous arteriovenous haemofiltration has become recognised as a useful technique for the correction of hypervolaemia, electrolyte imbalance, and metabolic acidosis secondary to renal failure in critically ill children. ${ }^{3}$ Continuous arteriovenous haemodiafiltration is a modification of 